Fecha de recepción: agosto 2014 Fecha de aceptación: octubre 2014 Versión final: marzo 2015

\section{Nuestra inserción en la cadena de construcción nacional}

Pelusa Borthwick *

Resumen: El presente escrito realiza un racconto de las primeras aproximaciones al arte tecnológico haciendo hincapié en las distintas ediciones de FASE

Palabras clave: tecnología - encuentro - proyección nacional y latinoamericana.

[Resúmenes en inglés y portugués en la página 35]

${ }^{(*)}$ Curadora - Directora de FASE - Docente del posgrado de Lenguajes Artísticos Combinados del IUNA.

Intentamos esta inserción desde el Arte, en diálogo con los otros agentes, concientes de que la obra de arte siempre ha sido un objeto para el conocimiento. Analizamos el espíritu de nuestra época y sus manifestaciones artísticas intuyendo que las diversas estéticas que sobrepasan la aceptada pluralidad de lenguajes del arte contemporáneo al igual que los modos de hacer visible el mundo y sus límites, nos presentan universos dominados por la ambigüedad.

El cruce entre ciencia, arte y tecnología nos parece un campo que demanda una reflexión y análisis del tiempo en que vivimos. Por eso, nos pusimos a trabajar y creamos -FASE/ Encuentro- a comienzos del año 2009.

La tecnología está instalada en la sociedad e impacta nuestras vidas en profundidad. Actos mecánicos como mirar TV o subir a un avión rara vez nos solicitan algún tipo de análisis ni nos interrogan sobre la larga ruta transitada por las sociedades y las tecnologías para poder brindarnos esta infraestructura de cotidianidad. No olvidemos que los procesos de innovación tecnológica son fundamentales para comprender los cambios sociales y económicos. Y allí está el Arte con su aporte de creatividad en la forma de transgresión, desafío, desestabilización y fragmentación de la vida diaria, generando diferentes políticas públicas y privadas que nos convocan a la acción.

Con la curaduría general de Graciela Taquini dirigí las primeras cuatro ediciones de FASE en forma individual. Desde la quinta edición comparto esta función con Marcela Andino y Patricia Moreira quienes fueron y siguen siendo las productoras del evento.

Presentamos FASE 1 en el Centro de Exposiciones de la Ciudad Autónoma de Buenos Aires del 29 al 31 de Mayo de 2009 bajo la denominación abarcadora: "El estado de la cuestión". Varias instituciones estaban trabajando el cruce entre ciencia, arte y tecnología y decidimos entonces nuclearlas en un punto de encuentro que nos permitiera profundizar los vínculos 
existentes tanto como las reflexiones y promociones de proyectos y obras. Recordemos apenas algunos eventos que surgen al inicio de ese tiempo de las artes electrónicas. Así, en 1995 se presenta FIV - Festival Internacional de Video y Artes Electrónicas de Buenos Aires I, en el Centro Cultural Recoleta y al año siguiente la segunda edición en el Teatro General San Martín, ambas coordinadas desde la dirección artística por Carlos Trilnick.

En 1997 se presenta Ciclo de Arte Sonoro Experimental en el MAMBA - Museo de Arte Moderno de Buenos Aires, coordinado por Jorge Haro y el año anterior Anahí Cáceres había creado arteUna, plataforma para la difusión del arte en Internet.

En la muestra Arte Siglo XXI en el Centro Cultual Recoleta (1998) Rodrigo Alonso presentó obras digitales y video-instalaciones y en el área de reflexión incluyó mesas redondas sobre Arte y las nuevas tecnologías y Arte en Internet. Un año después Gustavo Galuppo y Germán Villareal organizan Videodromo, muestra internacional de video experimental en el Teatro Municipal Mateo Booz de Rosario.

En el año 2000, tras la positiva experiencia que había sido Belgrano Puertas Abiertas presentado por Pelusa Borthwick y Luz Castillo congregando instituciones en el barrio de Belgrano, Ana María Battistozzi, con la producción del Ministerio de Cultura de la Cidad de Buenos Aires pesentó Estudio Abierto incluyendo algunas piezas de video y arte tecnológico.

También Internacional del Museo Nacional de Bellas Artes, organizada por Jorge Glusberg. En 2001 se crea en la ciudad de La Plata Proyecto Biopus dedicado a la producción de arte tecnológico interactivo y en la Alianza Francesa de Bs. As. Graciela Taquini inaugura la exposición Trampas (en torno al simulacro) que incluye propuestas de arte digital y videos. $\mathrm{Al}$ año siguiente la Fundación Konex otorga el Premio Konex de Platino en la categoría arte digital a Gustavo Romano y en la categoría videoarte a Charly Nijensohn.

En 2003 en Muntref - Museo de la Universidad 3 de Febrero se inaugura Untref Electrónico con obras de profesores y alumnos de la carrera que se dicta en dicha universidad. Un año después se realiza la tercera edición del Premio MAMBA y Fundación Telefónica de Arte y Nuevas Tecnologías y el ICI - Instituto de Cooperación Iberoamericana presentan una retrospectiva del Festival Buenos Aires Video.

En 2005 se inicia el Taller de Arte Interactivo en EFT - Espacio de Fundación Telefónica, programa de análisis y discusión de proyectos artísticos para las nuevas tecnologías. En 2006 el Centro Cultural Recoleta abre sus puertas al festival audiovisual Onedotzero y se crea Proyecto Untitled colectivo pedagógico artístico integrado por directivos, alumnos y docentes de la Escuela de Diseño y Comunicación Multimedial de la Universidad Maimónides.

En el año 2007 Antoni Muntadas expone en Buenos Aires con curaduría de Laura Buccellato. Así se multiplican en forma exponencial los eventos y cursos relacionados con el tema que nos ocupa e iniciados en años anteriores cuya mención desborda el alcance de este texto. En 2008 se inaugura Objeto a, espacio dedicado al arte tecnológico y que tiempo después creará la Bienal Kosice.

En 2009 sucede, entonces, la primera edición de FASE. Decíamos en su texto introductorio que quien visitara FASE 1 iba a desplazarse por un territorio muy rico y diferente donde cada obra era una entidad autónoma pero la relación entre ellas brindaba una unidad de signo mayor. Agregábamos que nos enorgullecía esa entrega a la comunidad a través de un evento de entrada libre y gratuita. Dejamos constancia que esos lineamientos originales continúan en la actualidad cuando nos encontramos en la etapa de preproducción de la 
sexta edición que presentaremos nuevamente en el Centro Cultural Recoleta a fines del mes de Octubre del corriente año.

Entre el 2 y el 6 de Junio de 2010 presentáramos la segunda edición. Decía, desde la dirección del evento, que en el tiempo y el espacio del Bicentenario recordamos lo acontecido y nos preguntamos por lo que vendrá. FASE 2 nos interrogaba bajo el título de cómo “¿Te ves en el futuro?" La exposición y su marco argumental estaban allí presentes como el punto de partida para el ejercicio de lectura de la misma y el debate posterior. Destacamos que en el espacio de reflexión que se llevó a cabo en el CEDIP (Centro Cultural Recoleta) analizamos con especial atención lo ya realizado y los proyectos en vías de concreción. Agregábamos, en esa oportunidad, que desde el arte contemporáneo, unidos a los artistas y al público en general, las instituciones y las galerías de arte reflexionamos sobre las poéticas generadas por los nuevos soportes de la ciencia y la tecnología.

Hoy, reiteramos que el arte nos hace ciudadanos más libres, innovadores y conscientes de nuestro rol en la sociedad y que desde el equipo organizador del evento aseveramos que somos responsables de la permanente construcción del proyecto FASE.

La tercera edición propuesta bajo el eje temático de "Zona de prueba" tuvo lugar entre el 5 y 8 de Mayo de 2011 y la dedicamos a la memoria de Luis Fernando Benedit quien había fallecido el mes anterior.

En el texto de mi autoría que publicamos en el catálogo de FASE 3 mencionaba:

En diálogo con Rodrigo Alonso sobre la historia del cruce de ciencia, arte y tecnología en Argentina, recordamos a Xul Solar quien, en la década del 20, nos introdujo en su universo imaginario de estructuras mecánicas y máquinas voladoras reflejando así un mundo que da cuenta del progreso tecnológico. En la década del 40 los artistas concretos y Madí incrementaron las referencias al tema y más tarde las esculturas de neón creadas por Gyula Kosice en 1946 sentaron las bases, en nuestro país, de la interrelación entre arte y tecnología. En 1951 Lucio Fontana presentó el Manifiesto del Movimiento Espacial para la televisión, y este fue uno de los antecedentes del desarrollo del video arte. Diez años más tarde, en 1960, el Grupo parisino GRAV (Groupe de Recherche d-Art Visuel) produjo arte cinético, buscando la expansión de los límites entre arte y vida. En 1966 Marta Minujín exhibió una serie de obras exaltando la presencia de los medios en la vida cotidiana. Entre fines de los 60 y comienzos de los 70, Leopoldo Maler, Lea Lublin, David Lamelas y Margarita Paksa presentaron al público obras que hay llamaríamos video instalaciones mientras Victor Grippo y Luis Benedit trabajaban con energía vegetal. El Instituto Di Tella y el CAYC dieron cabida a importantes obras experimentales.

Las visiones utópicas que habían caracterizado las producciones antes mencionadas fueron, en adelante, reemplazadas por imágenes más cercanas al análisis de la realidad. Usando los instrumentos provistos por la tecnología, los artistas devienen escrutadores de la realidad y analistas de los sistemas y procesos que la conforman a la vez que exégetas de construcciones discursivas, materiales e ideológicas. 
FASE 3 tenía como objetivo lograr una muestra interactiva y participativa que propiciara vivencias personales. Esta exposición se proponía formar al público y a partir de allí alentar su disfrute así como debatir colectivamente el desarrollo que Arte y Tecnología habían alcanzado hasta el momento a través de presentaciones de artistas, teóricos, profesores y estudiantes y la exhibición de obras presentadas por galerías de arte, centros culturales, asociaciones, fundaciones y museos nacionales e internacionales.

Reconocemos al campo artístico como principio mediador entre el arte y el público y bien sabemos que parte de ese público considera a las distintas tecnologías como continuación del cuerpo humano y amplificador de sus capacidades. Tengamos presente también que sus imágenes se revelan como núcleos de significación sobre los que oponentes y seguidores de los soportes del arte electrónico continuamos reflexionando y enriqueciéndonos con el debate. El proyecto FASE continúa así prestando especial atención a las discusiones sobre el tema.

No es de olvidar la responsabilidad de los artistas y sus promotores de pensar críticamente su época. Michael Foucault nos ha enseñado que la labor crítica del pensamiento es tratar de saber cómo y hasta donde es posible pensar de otra manera y no legitimar lo que ya es conocido.

Entre el 11 y el 14 de Octubre de 2012 presentamos FASE 4 con el eje conceptual "Postecologia. Hacia una naturaleza y una cultura sustentables" e iniciamos el programa anual de homenajes reflexionando sobre la obra de Gyula Kosice.

Para esa edición del evento escribí en el catálogo sobre nuestra creencia de que cuidar el ambiente es cuidarnos a todos nosotros y nosotras, a lo que nos rodea y a nuestro patrimonio natural y cultural, que todo está conectado y que cada parte hace al todo. Decía también que el prefijo post es un llamado de atención al descuido con que tratamos la Ecología y a las graves consecuencias que se están produciendo en este orden. En este sentido, continuamos afirmando nuestra propuesta de crear desde el arte una nueva mirada hacia ese tema esencial para la supervivencia del planeta acercándonos a la realidad a través de vivencias de indagación y relacionándonos con las contradicciones que aparecen. Somos conscientes y, nos ocupa el problema de la destrucción de recursos, integrada a la degradación ambiental que tiene origen en el proceso de crecimiento junto a la globalización económica con sus más y sus menos y que se encuentran íntimamente ligadas a la destrucción de valores culturales unidas a identidades y prácticas productivas.

Presentábamos FASE 5 entre el 8 y el 11 de Noviembre de 2013 respondiendo al eje temático "Metáforas de la supervivencia / La fragilidad de los entornos de la naturaleza y el arte". En esta edición realizamos dos homenajes: al maestro pionero Victor Grippo y a la artista contemporánea Anahí Cáceres por su sitio arteUna creado en 1996.

En mi carácter de curadora de la exhibición de Anahì Cáceres, artista oriunda de Córdoba quien se instala en Buenos Aires a comienzos de la década del 90, escribí y reafirmo que ella es un referente de su generación en la expresión cabal de su tiempo, y que utiliza los diversos lenguajes y técnicas que ese tiempo le reclamaba. Anahí ha sido una adelantada exploradora de la web creando arteUna que, con su realidad múltiple, permite a los artistas ingresar en esa otra realidad llamada virtual.

En el texto general que produje para esa quinta edición me propuse comentar el cruce del arte moderno al contemporáneo analizando los propios andamiajes institucionales y sus 
redes de supervivencia cada uno en su propio tiempo histórico, mostrando sus estructuras de permanencia y de cambio.

Allí decía:

Comprendemos que las prácticas artísticas contemporáneas despliegan modos de hacer y proyectos que nos interrogan y generalmente no nos proponen certezas. Estas prácticas se diferencian y se separan del arte moderno que continúa siendo muy significativo en la vida y los valores de gran parte de la sociedad. FASE es arte contemporáneo y en consecuencia continúa presentando obras y proyectos que nos llevan a reflexionar y a accionar desde circuitos artísticos no convencionales. El diálogo establecido entre percepciones tan diversas genera sentidos insospechados y nos hace apoyar escenarios divergentes que se han transformado en una verdadera apuesta de investigación en el medio del arte y la cultura.

Mi deseo al finalizar ese texto, aquí comentado, indicaba que los ojos del mundo miran la integración de América Latina. Me complace agregar que este ha sido el deseo de FASE desde sus inicios a través de sus organizadores, curadores y artistas participantes. Esta propuesta de análisis y acción ha sido el eje de nuestro trabajo y debemos confesar nuestro enamoramiento del proyecto que día a día construimos y del que nos apropiamos.

Estamos creando parte de la herencia simbólica de nuestro país y por este medio los invitamos a todos y todas a acompañarnos.

Summary: The article describes the early approaches to technological art emphasizing in FASE's different editions.

Keywords: technology - meeting - national and Latin American projection.

Resumo: Este artigo aborda as primeiras manifestações da arte tecnológica fazendo ênfase nas edições de FASE.

Palavras chave: tecnologia - encontro - projeção nacional e latino americana. 
